\title{
MUSSOLINI LAS QUIERE DEPORTISTAS: MUJER Y DEPORTE EN LOS NOTICIARIOS CINEMATOGRÁFICOS LUCE (1928-1943)
}

\author{
Carlota Coronado Ruiz \\ Universidad Complutense de Madrid
}

Recibido: 05/02/2013

Aceptado: 27/03/2013

\section{Resumen}

Este artículo analiza la imagen que el noticiario cinematográfico Luce presentó de las mujeres del mundo del deporte entre 1928 y 1943. Se utiliza como fuente los noticiarios Luce porque constituyó uno de los instrumentos fundamentales de la propaganda fascista. Se estudia la evolución de la representación de la mujer en diferentes ámbitos del deporte, así como la política fascista relacionada con el deporte femenino y el culto del cuerpo.

Palabras clave: Mujer, Italia, Deporte, Noticiarios cinematográficos, Luce, Fascismo.

\begin{abstract}
This article analyses the sportswomen's image during the Mussolini's regime, from 1928 to 1943, as shown in the Luce news bulletins. These bulletins are used as a source because they were one of the key instruments of the fascist propaganda. We study the evolution of representation of sportswomen, as well as the fascist politicies about women's sport and the cult of the body.
\end{abstract}

Keywords: Women, Italy, Sport, Newsreel, Luce, Fascism. 



\section{Introducción}

En febrero de 1933 la publicación femenina Il giornale della donna pedía a sus lectoras que enviasen fotografías que mostraran a mujeres en distintos ámbitos, desde la madre de familia numerosa a la mujer con uniforme de los Fasci; trabajadoras; mujeres en campos coloniales, etc. El fin de esa campaña era definir el tipo de mujer de la Revolución fascista. Cada fotografía representaba una realidad distinta de la sociedad de entonces: se hacía así patente la pluralidad de modelos femeninos. En los medios de comunicación de la época, así como en el noticiario Luce, además del difundido modelo de esposa y madre, se ponen de manifiesto otros modelos femeninos, cánones de belleza distintos a los defendidos por el Régimen: desde la mujer deportista a la actriz de moda.

Ello denota que la imagen pública de la mujer que se proyecta a través del noticiario oficialista Luce puede llegar a ser muy distinta a la que normalmente se asocia a la mujer fascista. Noticias como las relacionadas con el deporte contribuyen a crear una representación distinta a la oficial. Muchas de las mujeres que protagonizaban estas noticias se convirtieron en modelos de referencia para las espectadoras de la época. Las modas, el aspecto físico y los comportamientos, que se veían en la pantalla, se imitaban. Por ello, el Régimen pretendía establecer un canon de belleza y unas modas acordes a la ideología fascista: «poder definir la belleza de una mujer es también un modo de relegarla a un papel subordinado» ${ }^{1}$.

El cine tiene una gran capacidad para orientar el pensamiento y el comportamiento de los espectadores. Un periodista como Mussolini sabía que la cinematografía era el arma más fuerte: el público interioriza modelos y estereotipos de referencia presentes en el cine. Se producen mecanismos de proyección y de identificación con las figuras que aparecen en la pantalla de cine ${ }^{2}$.

1. De GRAZIA, Vittoria. Le donne nel regime fascista. Venecia, Marsilio Editori, 1993, p. 287.

2. Zagarrio, Vito. Cinema e fascismo: film, modelli, immaginari. Venecia, Marsilio, 2004, p. 24-25. 
En un contexto como el autoritarismo fascista, el cine es un instrumento encaminado a reforzar la socialización de consensos colectivos ${ }^{3}$. La política y la vida pública de los jerarcas del Régimen se convirtieron en espectáculos de masas, y la ideología fascista contaminó tanto el cine de ficción como los noticiarios. El gobierno fascista puso todo su empeño en conseguir, a través del cine, una persuasión efectiva en el público ${ }^{4}$. De esta manera, el gobierno de Mussolini intentó establecer un control mediático e imponer una serie de modelos femeninos a través del cine.

Sin embargo, aunque el noticiario Luce constituyera uno de los instrumentos fundamentales de la propaganda fascista por sus características -obligatoriedad de exhibición y monopolio de la información ${ }^{5}$-, el modelo femenino que difundió y trató de imponer el noticiario a través de las informaciones relacionadas con el mundo del deporte, apenas cuajó en la sociedad italiana. La fuerza persuasiva y el impacto de otros medios de comunicación en esos años, básicamente el cine de ficción procedente de Hollywood, eran mucho mayores, sobre todo entre la población femenina.

Por ello, en este estudio, se aborda el cine durante el fascismo italiano desde una perspectiva innovadora, despegada de la interpretación clásica, centrada en el análisis de contenido del cine más declaradamente político, o del de temática histórica o épica, entendiéndolos como cine de propaganda explícita. Ello permite cuestionarse la existencia de otros productos mediáticos de consumo cotidiano, como eran los noticiarios cinematográficos, como soportes eficaces para la circulación y transmisión social de referentes de género.

También se pretende resaltar la importancia de los noticiarios como fuente para el estudio del entretenimiento colectivo durante el fascismo, más allá de su sentido obviamente informativo. Pero, el objetivo principal de este artículo es mostrar cuál fue la imagen cinematográfica pública de la mujer, cuáles fueron los estereotipos públicos de género relacionados con el mundo del

3. Sobre este tema se pueden ver: MIDA, Massimo (Coord.). Dai telefoni bianchi al neorealismo. Roma-Bari, Laterza, 1980; ZAGARRIO, Vito. Cinema e fascismo: film, modelli, immaginari. Venecia, Marsilio, 2004.; BRUNETTA, Gian Piero. Intellettuali, cinema e propaganda tra le due guerre. Bolonia, Patron, 1972; REDI, Riccardo (dir.). Cinema italiano sotto il fascismo. Venecia, Marsilio, 1979.

4. Ver Montero, Julio y PAZ, María Antonia. Creando la realidad. El cine informativo. 18951945. Barcelona, Ariel Comunicación S.A, 2002, pp. 187-225.

5. Como señala Gigliola Gori, el noticiario se proyectaba además de en las salas de cine, en escuelas o en ayuntamientos, lo que ampliaba su difusión (GORI, Gigliola. Italian fascism and female body. Sport, submissive women and strongs mothers. Nueva York, Routledge, 2004). 
deporte, así como su evolución desde 1928 hasta entrada la guerra, y hasta qué punto se instrumentalizó el imaginario femenino.

El cine y los noticiarios cinematográficos ayudaban a configurar estos modelos femeninos, muchas veces muy alejados de los cánones de belleza fascistas. Así, en este estudio se pretende poner en evidencia los diferentes modelos femeninos difundidos por el noticiario Luce: algunos distintos e incluso complementarios a los que la propaganda fascista pretende imponer; otros, basados en el canon de belleza fascista de mens sana in corpore sano. Con este objetivo se analizan algunas de las características que, desde la construcción audiovisual, se establece de las mujeres que protagonizaban las noticias sobre deporte: desde su aspecto o el tipo de deporte que llevan a cabo, la vestimenta que lucían, hasta los valores que representan, las pautas de comportamiento que difunden, etc. ${ }^{6}$.

\section{Metodología}

Para llevar a cabo este estudio se han visionado los noticiarios sobre el mundo del deporte en los que estaban presentes las mujeres, entre 1928, año en del primer noticiario cinematográfico que se conserva en el Archivo Luce, y 1943 año que marca la caída del Régimen de Mussolini.

Un noticiario cinematográfico ofrece muchas lecturas. Una, es descubrir, a través de sus imágenes, cómo quiere la sociedad de ese momento, ser vista o cómo quiere que la vea el espectador. En el caso de este artículo, un aspecto distorsiona este principio general, aunque resulta muy útil en el empeño: lo que las autoridades quieren mostrar -lo que los redactores suponen que pueden y deben mostrar- tiene un peso definitivo; pero precisamente este factor facilita la comprensión de la imagen que se quiere promover.

La utilización de un medio de comunicación, como los noticiarios cinematográficos, para la difusión de unos determinados modelos de mujer, exige una metodología específica porque el modo de difundir los mensajes presenta tanto interés como los contenidos de los propios mensajes. Efectivamente, desde los temas tratados, al modo de presentarlos, o los grupos sociales protagonistas de las noticias, sirven para establecer el tipo de mujer, el estereotipo femenino, que se quiere difundir a través de los medios de comunicación en los distintos periodos. Por ello, se ha llevado a cabo una metodología de

6. Sobre la relación entre el deporte y el cuerpo femenino durante el fascismo existen varios estudios, entre ellos ISIDORI, FraSCA, Rosella. Il duce le vuole sportive. Bolonia, Patrón Editore, 1988; y uno de los más recientes, GORI, Gigliola. Italian fascism and female body. Sport, submissive women and strongs mothers. Nueva York, Routledge, 2004. Ninguno se centra en la representación cinematográfica de la mujer en el ámbito del deporte. 
análisis que ha permitido analizar tanto la forma como el contenido de las imágenes audiovisuales.

Se han tenido en cuenta recientes estudios sobre la ubicación y comprensión de la imagen en un contexto histórico y sociocultural, es decir, la Nueva Historia Cultural ${ }^{7}$. Siguiendo este enfoque, la imagen se sitúa en las coordenadas de su producción, las de su difusión, y, finalmente, las de su recepción y consumo. A esta línea de investigación se suman los estudios que se centran en los olvidados de la Historia, niños y mujeres, que no tienen apenas presencia en las fuentes escritas y sí en los materiales audiovisuales.

Partiendo precisamente de este modelo de análisis, se elabora una metodología específica para los objetivos que aquí se han propuesto y el tipo de fuentes utilizadas. En primer lugar, se ha contabilizado el número de las noticias relacionadas con mujeres y el deporte, para saber el grado de protagonismo que tenía este tema dentro del noticiario. Este número se ha relacionado con el total de noticias producidas. También se comparan los datos numéricos relacionados con diferentes temas dentro del mundo del deporte para saber cuáles son las noticias más abundantes, qué temas se repiten más, qué tipo de mujer es la más difundida. De esta manera se puede establecer qué modelos de mujeres aparecen en los noticiarios sobre el mundo del deporte, a qué clase social pertenecen, qué actividad realizan, con qué contexto están relacionadas o cómo se construyen las relaciones de género, entre otros aspectos. A partir de este análisis, se puede saber cuál es la representación de la mujer dentro del deporte que más se repite en el noticiario Luce y por tanto la más difundida, así como los temas más tratados y los menos tratados.

En la selección de noticias se han descartado aquellas en las que la mujer no tenía presencia alguna. Aunque es un dato significativo la exclusión de ésta en la mayor parte de las noticias de relevancia sobre el mundo del deporte, se ha optado por centrar el análisis sólo en las noticias en las que la mujer aparece físicamente. De esta forma se determina el modo en el que los noticiarios presentan a la mujer y se valora en qué tipo de noticias aparece o protagoniza. Finalmente, las noticias seleccionadas, vistas y analizadas han sido un total de cincuenta y una. Estas noticias, de una duración aproximada de entre uno y cuatro minutos, forman parte de noticiarios producidos entre 1928 y 1943, estructurados en diferentes secciones (nacional, internacional, obras públicas, industria, etc.). Dentro de estos noticiarios, la relevancia de este tipo de informaciones sobre la mujer italiana y el deporte es escasa: su

7. Cfr. verse Martínez MARTín, Jesús. «Debate y propuestas para una historia de la transmisión cultural», en Cultura y Civilizaciones. III Congreso de la Asociación de Historia Contemporánea, Universidad de Valladolid, 1998, pp. 125-127. 
duración es menor de la media de otro tipo de noticias, y su colocación dentro de la estructura del noticiario es marginal.

En segundo lugar, se ha realizado un análisis de contenidos con el fin de establecer cuáles eran los estereotipos femeninos más difundidos, los temas principales de los noticiarios, así como las ausencias más destacadas. Para llevar a cabo la selección de noticias y el análisis de contenidos, ha sido necesario un apoyo bibliográfico. Se han tenido en cuenta otros estudios que han abordado los noticiarios cinematográficos como fuentes documentales, y, en especial, los noticiarios $\mathrm{Luce}^{8}$ como instrumento fundamental para la propaganda del fascismo.

También se ha prestado atención a la forma de los noticiarios para establecer hasta qué punto lo que se presenta tiene una intención más allá de la mera información. Para ello se ha realizado un análisis del lenguaje cinematográfico utilizado: tipos de planos y sus intenciones propagandísticas, uso del montaje, significados del sonido y de la música en contraste con la imagen para crear nuevos conceptos, entre otros aspectos.

En definitiva, se pretende presentar una perspectiva sintética sobre un corpus documental amplio (noticiarios, 1928-1943), atendiendo a los caracteres de cambio y estabilidad en la representación de una tipología femenina concreta (la mujer ligada al mundo del deporte), desde un marco de reflexión coherente con la metodología aplicada en los estudios sobre construcción social de la realidad.

\section{Resultados}

\subsection{El Duce las quiere deportistas: ideología fascista sobre el deporte femenino}

El régimen de Mussolini pretendía acabar con la influencia de modelos femeninos perniciosos para la mujer: aquellos que les desviaran de su función natural. Así, se debía contrarrestar tanto los viejos modelos - de la mujer romántica y sentimental-, como los más modernos -que procedían de América. Según el discurso oficial, estos modelos tenían que ser sustituidos por el de una mujer práctica, activa, que ama el ejercicio físico y desprecia el ocio: una «donna

8. Entre las publicaciones más destacadas en este sentido se encuentran CARDILLO, Massimo. Il duce in moviola: politica e divismo nei cinegiornali e documentari «Luce». Bari, Dedalo, 1983; BERNAGOZZI, Giampaolo. Il mito dell'immagine. Limmagine del mito. Bolonia, Editrice Clueb, 1983; y entre las más actuales cabe destacar dos tesis: INGIUSTO, Dario. Cinegiornali dell'Istituto Luce: linguaggio, propaganda e consenso nell'Italia fascista, http:// www.tesionline.it/default/tesi.asp?idt=17526\&forceCom=y, 2004; y GIOMETTI, Sophie Elisa, Finte verità per veri interesi. Evoluzione del documentario di propaganda política, http://www.tesionline.it/default/tesi.asp?idt=39507\&forceCom=y, 2011). 
nuova $»^{9}$. Para este tipo de mujer, como señalan Motti y Rossi Caponeri, la educación deportiva es un factor esencial e indispensable.

La mujer fascista debe ser físicamente sana, para poder convertirse en madre de hijos sanos (...) Por ello, deben ser eliminadas las imágenes de figuras femeninas artificiosamente delgadas y masculinas, que representan el tipo de mujer estéril de la decadente civilización occidental ${ }^{10}$.

Este estereotipo estaba representado por las modelos y actrices de cine: mujeres delgadas, teñidas de rubio platino y que llevaban pantalones. El Régimen trató de eliminar su presencia en los medios de comunicación y en la publicidad, e intentó crear nuevas referencias más acordes con la «nueva italiana». Por tanto, frente al tipo de mujer moderna, la llamada donna-crisi-tumba de la feminidad y de la maternidad-, se encuentra otro modelo de mujer que no es la madre y esposa, pero que representa una serie de valores positivos para el Régimen, como la salud del cuerpo y la juventud. Son las mujeres que aparecen en las noticias sobre deporte.

El deporte es una expresión de un sistema sociocultural, porque constituye un reflejo de los rituales y valores de las sociedades en las que se desarro$\operatorname{llan}^{11}$. Como sostiene Patrizia Ferrara, en la Italia fascista, el deporte femenino está muy estrechamente relacionado con la batalla demográfica, por lo que se convirtió en una de las cuestiones políticas de mayor urgencia ${ }^{12}$. Para los ideólogos del Régimen la finalidad del deporte era formar buenas madres cristianas, fuertes y sanas, física y moralmente, capaces de dar una generación de italianos sanos, buenos, también ellos física y moralmente.

El principio latino de mens sana in corpore sano no debía ser sólo patrimonio masculino. La madre, encargada no sólo de la gestación, sino también de la nutrición del recién nacido, tenía que estar necesariamente sana. Para conseguir este objetivo, el Régimen creó en 1923 el Ente Nazionale per l'Educazione Fisica, cuyo objetivo era establecer la educación física como materia obligatoria en todas las escuelas del Reino de Italia ${ }^{13}$.

Hasta esta fecha, tanto las prácticas deportivas de las mujeres como la educación física se habían descuidado: las actividades físicas eran sinónimo

9. Ferrara, Patrizia. «La 'donna nuova' del fascismo e lo sport», en Canella, Maria y Giuntini, Sergio (Eds.). Sport e fascismo. Milán, Franco Angeli, 2009.

10. Círcular para la prensa de 1932, en MotTI, Lucia y Rossi CAPONERI, Marilena. Accademiste a Orvieto. Donne ed educazione física nell'Italia fascista (1932-1943). Perugia Quattroemme, 1996, p. 54.

11. Vid. Guttmann, Allen. Women's sports: A History. Nueva York, Columbia University Press, 1991.

12. Ferrara, Patrizia. Op. cit., p. 209-212.

13. Motti, Lucia y Rossi Caponeri, Marilena. Op. Cit., p. 27. 
de virilidad. La concepción del cuerpo era, además de machista, de fuerte inspiración belicista:

El cuerpo del hombre se considera el lugar del proceso físico, de una mejora de la raza, de una potenciación de las capacidades de trabajo. El cuerpo masculino es el único que se considera como lugar de cultura, sede de valores. Y sólo es el cuerpo del hombre el que es interpretado históricamente, en él está el futuro, el cambio. El cuerpo de la mujer, más allá de los cambios somáticos, biológicos y fisiológicos, desde el punto de vista social y cultural, es algo perennemente igual a sí mismo, que no cambia nunca ${ }^{14}$.

El cuerpo femenino se consideraba como una máquina moderna de reproducción social: la única función que se le puede atribuir es la de mejorar el físico de las generaciones futuras, y en especial, de los soldados. Así pues, aunque el deporte femenino se considerase antinatural, se concibió un tipo de deporte que ayudara a la mejora de la raza: la gimnasia podía mejorar las deficiencias en el desarrollo de la mujer -sin dañar su gracia y decoro-, y prepararla para su misión histórica de madre. «Sólo a través del deporte la mujer se puede preparar para convertirse en una madre vigorosa y sana, lista para hacer frente al peligro por la defensa de los sagrados confines, y para cualquier tipo de sacrificio por la potencia de la Patria» ${ }^{15}$.

Pero no toda la sociedad italiana estaba de acuerdo con estas ideas. Los sectores más conservadores pensaban que era una «degeneración ética», además de una invasión de un terreno masculino: «habéis querido salir fuera de los confines que os ha asignado la naturaleza. En vez de ser colaboradoras del hombre, os habéis convertido en sus competidoras hasta en el deporte» ${ }^{16}$.

El mismo Papa se había pronunciado contra el deporte femenino en la encíclica Casti Connubi de 1930, donde había subrayado que la única función social de la mujer era el matrimonio y que el trabajo fuera de la propia casa representaba «una corrupción de la índole femenina y de la dignidad materna, perversión de toda la familia» ${ }^{17}$.

Aunque para el fascismo el deporte era la manifestación cultural más importante del país ${ }^{18}$, existía la convicción de que el deporte era perjudicial para

14. MotTI, Lucia y Rossi CAPONERI, Marilena. Op. cit., p.9.

15. Gemelli, Agostino. L’educazione fisica della donna. Volumen III. Milán, Soc. Edit. Vita e pensiero, 1926, p. 32.

16. Follacchio, Sara. «Donne e modelli culturali nel ventennio», en Trimestre, número $1-2,1985$, p. 8.

17. Pío XI, cit. en Momigliano, Eucardio. Tutte le Enciclicle dei Sommi Pontefici. Milán, Dall'Oglio, 1974, p. 894.

18. Viuda-Serrano, Alejandro y GonZÁlez AjA, Teresa, «Héroes de papel: El deporte y la prensa como herramientas de propaganda política del fascismo», en Historia y Comunicación Social, Volumen 17, 2012, p. 47. 
la mujer y para su capacidad de procrear, además de considerarlo perjudicial para la mujer porque la masculinizaba: la hacía perder atributos propios de su sexo, la transformaba estéticamente y le dañaba las funciones del aparato genital.

Detrás de estos prejuicios se ocultaba el temor a la difusión de nuevos estereotipos femeninos que tuvieran como consecuencia social el culto de la «machito» (maschietta), así como una americanización de las costumbres que podría acabar -pensaban- con las obligaciones que el fascismo había asignado a las mujeres ${ }^{19}$.

Por todo esto, el Régimen vio necesario cambiar la opinión pública -católica y rural-y demostrar que la educación física femenina era fundamental para la mejora de la raza: había que difundir la convicción de que para ser madres sanas y fuertes y dar a la Patria hijos igual de sanos y fuertes, las mujeres debían practicar actividad física y deportiva ${ }^{20}$.

Para hacer frente a los prejuicios en torno al deporte femenino, era necesario mostrar que la mujer no perdía su feminidad, ni olvidaba su misión maternal. La prensa, por ejemplo, se encargó de tranquilizar a los sectores más reaccionarios en relación con la formación de las deportivas de Orvieto:

Cae, se rompe el lugar común, el que hace creer a muchos que aquí se fabrican gimnastas, o cuanto menos, profesoras de gimnasia. No. Aquí se crean buenas, sanas, honestas y cultas madres de familia; aquí se crean las dirigentes, las organizadoras de las Casas de los Jóvenes, que tanta importancia tienen para la defensa de la raza propugnada por el Régimen (...) ¿Y la gimnasia? (...) Todos los ejercicios, el deporte, la gimnasia, acentúan su feminidad, no la eliminan ${ }^{21}$.

En la prensa de la época se subrayaban, además, la «gracia y la ligereza de los cuerpos femeninos» de las Academistas de Orvieto: «todos sus movimientos son exquisitamente femeninos y tienen una afinidad inconfundible con la danza $»^{22}$.

Como se ha podido comprobar en el estudio de los noticiarios fascistas, esta exaltación de los atributos femeninos también se presenta en el noticiario Luce. La voz en off que comenta las pruebas de gimnasia rítmica insiste en adjetivos como «gracia», «ligereza», «agilidad»: «en la prueba gimnástica anual de la G.I.L., 4.000 organizadas han participado, ofreciendo al público

19. VACCARI, Ida. La donna nel ventennio fascista (1919-1943). Milán, Vangelista Editore, 1978, pp.215-216.

20. De GRAZIA, Victoria. Op. cit., p. 267.

21. FABBRI, Sileno. L'Opera Nazionale per la Protezione della Maternità e dell'Infanzia, Milán, Mondadori, 1932, p. 19

22. Ibidem. 
un espectáculo de vigor y de gracia en el encantador escenario de los jardines de Boboli ${ }^{23}$.

En el noticiario, términos como «fuerza» se aplican sólo al deporte masculino. En la mujer hay que desarrollar la energía y el vigor, pero no la fuerza y la competitividad, típicamente masculinas. De esta manera, Luce subraya el «vigor» y la buena capacidad física de las deportistas: «las ágiles atletas en una serie de ejercicios vivamente aplaudidos por el público, se contienden la medalla de oro, dando amplia prueba de preparación deportiva y de sano vigor físico ${ }^{24}$.

Sin embargo, a pesar de todos los esfuerzos del Régimen por difundir una imagen positiva del deporte femenino a través de todos los medios a su disposición, la opinión dominante no cambió. Ante este clima, el Régimen tuvo que considerar de nuevo su política del deporte. Después de 16 de octubre de 1930, el Gran Consiglio impuso un férreo control en el atletismo femenino y en los deportes competitivos. Se pidió a un consejo de expertos en sanidad que establecieran cuáles eran los deportes que mejor se adaptaban a las mujeres. El principio fundamental que debía guiar la elección de un deporte era evitar todo cuanto «quisiera alejar a la mujer de su misión fundamental: la maternidad $»^{25}$.

\subsection{Los niños, fútbol. Las niñas, danza: deporte y género en los noticiarios Luce}

En la escuela, los niños se dedicaban al atletismo y las niñas a la gimnasia rítmica. Esta distinción por géneros tiene su reflejo en el noticiario fascista: hay una clara separación entre las noticias que tratan de deporte masculino y las de femenino. Raras veces aparecen en la misma noticia deportistas de ambos sexos, y si lo hacen, el montaje se encarga de dividir las imágenes de mujeres de las de hombres.

Después de realizar un análisis cuantitativo de las noticias visionadas, los resultados sobre la separación de géneros en las actividades deportivas, son los siguientes: del total de noticias analizadas sobre deporte, sólo en ocho $(10,7 \%)$ se presentan actividades deportivas de ambos sexos, y en todas ellas se establecen dos bloques de imágenes: hombres y mujeres no comparten plano. Además, se aprecia la diferencia en el tipo de deporte que cada uno

23. Giornale Luce C0147 (27-05-1941) «Actividades de la G.I.L. Prueba anual de la G.I.L. Presentes la princesa de Piemonte, la duquesa Ana D'Aosta y los principitos».

24. Giornale Luce C0063 (sólo año: 1940) «Atletismo femenino. Parma. Encuentro de equipos representantes de Italia y Alemania en el Estadio Municipal».

25. Poggi-Logostrevi. Cultura fascista della donna (de estetica femminile). Milán, Hoepli, 1938 , p. 45. 
practica: mientras los hombres practican boxeo, atletismo, lucha libre, ciclismo y esgrima, las mujeres se dedican a la equitación, la gimnasia rítmica o a deportes en equipo como el baloncesto ${ }^{26}$.

Esta clara división a través del deporte contribuía a crear una serie de roles que los niños adoptaban desde pequeños: la introducción de la educación física obligatoria en la escuela permitía la imposición de valores morales y sociales, así como el control, tanto físico como moral, de los jóvenes.

El ejercicio físico era concebido por el fascismo como una práctica social, un modo de socialización de jóvenes y adultos -sobre todo de aquellos que rechazaban el mensaje político directo ${ }^{27}$ - A través del deporte se produce una desindividualización y una despersonalización: el individuo deja de ser uno para convertirse en un colectivo. Las características individuales dejan paso a la homologación. Este aspecto se aprecia perfectamente en el noticiario Luce: los deportistas llevan el mismo uniforme, el de las organizaciones fascistas a las que pertenecen. Las atletas que muestra el noticiario lucen siempre camiseta blanca con la «M» o con las siglas de la «G.I.L.» y pantalones cortos negros. Pocas variaciones se aprecian en las gimnastas o bailarinas: todas ellas con falda negra y camisa blanca: siempre iguales, siempre uniformadas, siempre anónimas.

Así, a través del deporte, el fascismo se podía infiltrar de manera pacífica y sin contrastes entre los sectores más problemáticos de la sociedad. Se utilizaba el deporte para hacer creer a los jóvenes que desempeñaban un papel importante en la vida de la nación. De esta manera, el fascismo supo hacer de los jóvenes sus mejores aliados.

También el acto deportivo, así como lo concibe y lo practica el fascismo, refleja plenamente el trinomio mussoliniano: credere, obbedire, combattere (...) uno no se convierte en atleta, y por lo tanto en combatiente, si no se aprende a creer (...) si no se aprende a obedecer. Sobre todo en lo que es el gran mérito del deporte, gimnasio de educación física y moral, índice infalible de la voluntad de potencia en los individuos y en la nación ${ }^{28}$.

Después del análisis cualitativo de las noticias sobre deporte, se aprecia que éstas contribuyen a reforzar el mito de la juventud fascista. Se exalta la juventud como un valor en sí misma. Un cuerpo joven es un cuerpo sano. Por esta razón, las imágenes de Luce confieren especial atención a los cuerpos adolescentes de las deportistas: los uniformes blancos y los pantalones cortos

26. Como ejemplo: Giornale Luce C0149 (02-06-1941) «Vercelli. Actividades de la G.I.L.»

27. De GraZia, Vittoria. Le donne nel regime fascista. Venecia, Marsilio Editori, 1993, p. 248.

28. L'Illustrazione Italiana Sportiva, 1936. 
subrayan su juventud, además de su «gracia y valor», como subraya en ocasiones el narrador de Luce.

El deporte, la educación y la propaganda pretenden persuadir a los jóvenes del importante papel reservado para ellos en la sociedad fascista. Para el Régimen, el deporte cumple una doble misión: por una parte, enseña disciplina y obediencia, por otra, es fundamental para la formación político-cultural de los jóvenes. Se produce, por lo tanto, una identificación entre deporte y fascismo ${ }^{29}$.

Esta mezcla entre patriotismo y deporte es evidente en el noticiario del Régimen. En las noticias sobre deporte hay continuas exaltaciones del fascismo y de su líder: las coreografías de las gimnastas terminan en una enorme « $\mathrm{M}$ » que ocupa todo el césped del estadio; o en vítores y saludos estilo romano ${ }^{30 .}$

Deporte también se relaciona en Luce con disciplina y militarismo, sobre todo cuando se menciona a los niños. En las noticias en las que los pequeños Balilla ejecutan una prueba gimnástica, se marcan los movimientos geométricos y coordinados de los cuerpos con una música militar. En más del 30\% de las ediciones analizadas sobre deporte se insiste en la disciplina a la que se someten los jóvenes atletas ${ }^{31}$.

El militarismo es una característica común en la representación visual tanto de hombres como de mujeres. Aunque se acentúe más entre los hombres $^{32}$, el orden y la jerarquía militares dominan gran parte de las pruebas gimnásticas femeninas. En el deporte, la gimnasia se confunde con la marcha militar. Así, por ejemplo, en el Cine G.I.L. CG002, la G.I.L. (Gioventù Italiana del Littorio) llevará a cabo una prueba «gimnástico-militar». En otras noticias, mujeres de organizaciones fascistas, como los G.U.F. (Gruppi Universitari Fascisti), marchan en el Foro Mussolini de Roma -actual Estadio Olímpico- vestidas de uniforme militar y con fusiles.

La creación de la G.I.L. en 1937 llevó consigo un aumento del militarismo, lo que se hace patente de forma visual en los uniformes de las alumnas

29. ISIDORI FRASCA, Rosella. Il duce le vuole sportive. Bolonia, Patrón Editore, 1988, p. 149.

30. Cuando las deportistas italianas suben al podio hacen siempre el saludo fascista. En otras ocasiones, antes de la competición hacen el juramento al estandarte de los Savoia y ejecutan el saludo fascista. Como ejemplo: Giornale C0141 (05-05-1941) «Actividades de la G.I.L. de Montecatini. El V Campeonato de Gimnasia femenina se ha desarrollado ante la delegación alemana de la Hitler-Jugend».

31. Por ejemplo, en el Giornale Luce B0620 (sin día -02-1935) «El curso de esquí de las alumnas de la academia femenina fascista de Orvieto», el narrador dice: «Disciplinadas y alegres, sana práctica del deporte de las jóvenes dirigentes da la ONB, que durante su permanencia ha conquistado el afecto de todos los niños de la región».

32. En la academia de educación física masculina, se llevaban a cabo ejercicios militares, mientras que en la femenina éstos se sustituían con la economía doméstica. 
de la escuela de Educación Física de Orvieto que se ven en los noticiarios: el uniforme blanco y negro estilo enfermera es sustituido por la chaqueta y falda azul marino de tipo militar ${ }^{33}$. Hasta cambió el nombre de la rectora de la escuela, que pasó a llamarse «comandante».

El militarismo contribuye a una cierta ambigüedad de géneros. En la representación de las mujeres que pertenecen a las organizaciones fascistas se intenta transmitir un sentimiento de fuerza y agresividad, que en teoría iba unido al de protección materna. Pero, aunque la propaganda del Régimen insistiera en los atributos femeninos de las gimnastas, la imagen que se proyecta en los noticiarios, así como en el resto de medios oficiales, es la de mujeres fuertes y disciplinadas que se comportan y se mueven casi como soldados ${ }^{34}$ : cabeza en alto, busto erguido, barbilla hacia arriba.

Para contrarrestar este efecto indeseado, Luce insiste en la gracia y belleza de los movimientos de las gimnastas. La dulzura y armonía de las coreografías dominan en las imágenes sobre deporte recogidas por Luce en correspondencia con la doctrina oficial sobre la función del deporte en el desarrollo de la mujer.

\section{3. ¿Qué deportes puede practicar la mujer fascista?: representación de deporte femenino en Luce}

Aunque el Régimen defendiera la educación física femenina, no todos los deportes femeninos tenían el privilegio de aparecen en las pantallas cinematográficas. La elección del tipo de deporte que podían filmar las cámaras de Luce está relacionado con las directrices del Régimen sobre deporte femenino. Después de la polémica surgida entre los sectores más conservadores de la sociedad y los ambientes católicos ${ }^{35}$ por la imposición de la educación física

33. El nuevo uniforme unía características militares - paño azul, botones plateados, tela rígida- con un atención hacia los detalles que marcan el cuerpo femenino -la simetría entre la punta de cuello de piqué blanco atado sobre el hombro izquierdo y las dos puntas blancas de la camisa que sobresalen por la chaqueta corta y abierta.

34. El fascismo rescata también el mito griego de la amazona: la mujer de uniforme, armada. Pero resulta casi un contrasentido porque en el mito, el llevar armas está asociado con la virginidad, entendida como autonomía respecto a los hombres; la mujer armada se contrapone, por lo tanto, a la mujer-madre. (MOTTI, Lucia y RosSI CAPONERI, Marilena. Op. cit., p. 209).

35. La Iglesia era contraria al deporte femenino que consideraba pornográfico. Los sectores más conservadores de la sociedad iniciaron una campaña denigratoria de la actividad física femenina. L'Osservatore Romano, periódico del Vaticano, fue portavoz de la hostilidad de la Iglesia en relación con la difusión del deporte entre en las mujeres. Contribuyó a difundir la idea de que la atleta mujer atentaba al sentido común del pudor, además de ofenderlo, cuando se exhibía en competiciones deportivas que tenían un 
como materia obligatoria en la escuela, el Régimen tuvo que establecer una serie de deportes que podían practicar las mujeres.

Estos deportes son aquellos en los que la armonía y gracilidad femeninas se mantienen, puesto que «una musculatura demasiado desarrollada, no correspondería al ideal de la mujer italiana $»^{36}$. De este razonamiento se deduce que el deporte competitivo no se adapta a las mujeres: «éstas no han nacido para luchar, sino para procrear. Sin embargo, en los hombres, ser campeón es una salvaguarda contra la tendencia a la mediocridad, la mejor expresión de la raza ${ }^{37}$.

Como señala Teja, el fascismo varió su política en relación al deporte. En los años veinte, el Régimen seguía una orientación pedagógica e higiénica privilegiando la educación física como actividad grupal y menospreciando los deportes individuales de competición ${ }^{38}$. El objetivo era moldear el cuerpo y el carácter de los jóvenes según los ideales fascistas ${ }^{39}$.

Para el fascismo, la mujer debe hacer deporte, pero sin afán de competitividad, puesto que el deporte profesional, competitivo, «no puede siempre crear cuerpos normales y una buena salud $»^{40}$. Pero, además, no todos los deportes se adaptan a las características típicamente femeninas. Los que mejor lo hacen -según el fascismo- son: la gimnasia en general, el atletismo ligero, el tenis, esquí, esgrima y patinaje. Son todos aquellos que se presentan en los noticiarios Luce. El resto, deportes tales como el fútbol, el boxeo o el ciclismo, no eran apropiados para las mujeres.

El deporte estrella de los noticiarios Luce es la gimnasia, en sus varias facetas -rítmica y estética-. El 54\% de las noticias sobre deporte analizadas hacen referencia este tipo de deporte. El 56\% restante se lo reparten varias disciplinas: el atletismo representa un $18,5 \%$ del total; el patinaje, un $17 \%$; el esquí, un 6\%; la equitación, un 4,5\%; el tiro, baloncesto, tenis y canoa comparten el 10\% que resta. Ningún rastro de equipos de fútbol femenino ${ }^{41}$, ni de

público masculino que miraba más las formas voluptuosas de las atletas que el deporte en sí. (Rossi, Gaetano. Educazione fascista. Milán, Mondadori, 1942, p. 115).

36. Diel, Louise. La generazione di Mussolini. Milán, Mondadori, 1934, p. 39-40.

37. MOtTI, Lucia y RosSi CAPONERI, Marilena. Op. cit., p. 36.

38. TEJA, Ángela. «Deporte y relaciones internacionales durante el fascismo en Italia», en GONZÁlEZ AJA, Teresa (Ed.). Sport y autoritarismos. La utilización del deporte por el comunismo y el fascismo, Madrid, Alianza, 2002, pp. 241-243.

39. VeSCOVI, Roberta. "Children into Soldiers: Sport and Fascist Italy», en MANGAN, J.A. (Ed.). Militarism, Sport, Europe. War without Weapons, London, Frank Cass, 2003, p. 166.

40. Ibidem.

41. Las primeras noticias sobre fútbol femenino en Italia datan de 1930. En este año se fundó en Milán, el Gruppo Femminile Calcistico (Grupo Femenino Futbolístico). Al 
luchadoras o ciclistas. Parte de la opinión pública pensaba, como el periodista Colonnelli, que era una «barbarie, demostración evidente de gustos muy perversos (...) la idea de formar equipos femeninos de fútbol, de luchadoras, de ciclistas (...) caídas en el ridículo» ${ }^{42}$.

Es interesante también el hecho de que deportes como el atletismo aparecen sólo cuando hay manifestaciones de especial relevancia como campeonatos nacionales o internacionales. Sin embargo, las pruebas de gimnasia son una noticia recurrente: se presentan como manifestaciones de apoyo al Régimen. Así, el deporte se convierte en espectáculo pro-Régimen con unas características visuales que se repiten de una noticia a otra. Estas exhibiciones gimnásticas siguen un modelo de puesta en escena basado en la geometría y el contraste entre el blanco y el negro.

En primer lugar, para marcar las líneas rectas formadas por las gimnastas, se hace uso de los planos generales frontales que permiten ver la ejecución simultánea de un ejercicio en distintas filas, dando la idea de un cuerpo múltiple que se mueve al unísono: un mecanismo bien ordenado y sincronizado. Esta geometría se basa en el neto contraste entre el blanco y el negro. Éste se percibe mejor en los planos generales cenitales -captados desde las gradas del estadio- en los que el blanco y el negro crean un juego de líneas geométricas formadas por los perfiles de los cuerpos que se repiten o se unen. Los trazos que se crean son nítidos, marcados: se delimitan muy bien las zonas de luz y de sombra. No se trata de una estética propia, sino de la repetición del modelo de representación creado por los noticiarios y documentales nazis.

El uniforme es fundamental, no sólo para crear las figuras geométricas, sino también para dar una imagen de rigor y orden: todas tenían que ser iguales, porque un elemento de diferenciación era un elemento de desorden. Esta homogeneidad existía también en el aspecto físico: el pelo tenía que estar recogido, la mirada siempre fija y los gestos tenían que ser los mismos. Como se aprecia en el noticiario Luce, las gimnastas uniformadas formaban filas de idéntica altura: se colocaba a las más altas -y más guapas ${ }^{43}$ - delante, y se

contrario que las inglesas o alemanas, las futbolistas italianas jugaban con falda corta y no con pantalones. No existía una liga como la masculina. Hasta después de 1968, con la creación de la Federazione Italiana Calcio Femminile, no comenzará el campeonato de primera división con catorce equipos femeninos.

42. ISIDORI, FRASCA, Rosella. Il duce le vuole sportive. Bolonia, Patrón Editore, 1988, p. 303.

43. En la Academia de Orvieto se llevaba a cabo una selección de las chicas: no se admitía a aquellas que fueran demasiado bajas, demasiado gordas, que tuvieran leves defectos físicos o que llevasen gafas. En el reconocimiento médico, la rectora Lombardi decía al doctor que las cogiera idóneas, es decir, altas y guapas (MOTTI, Lucia y ROSSI CAPONERI, Marilena. Op. cit., p. 203). 
formaba una escalera, con las de menor altura en la última fila ${ }^{44}$. Pero, no sólo eran altas, también eran delgadas: aunque el canon de belleza condenaba a las delgadas, el exceso de peso no estaba tolerado entre las gimnastas ${ }^{45}$.

Aunque Luce dedica más noticias a las exhibiciones públicas de gimnasia, también aparecen otros deportes. En el noticiario se marca la diferencia entre los deportes practicados por la mayoría de las italianas y los de las élites. Las masivas manifestaciones gimnásticas eran el deporte del pueblo: las escuelas se encargaban de enseñar este tipo de ejercicios a las niñas desde muy temprana edad. Otros deportes que también se presentan en Luce, como el esquí o el patinaje, eran privilegio de una minoría ${ }^{46}$. Normalmente eran las hijas de las clases más pudientes las que frecuentaban este tipo de ambientes y de deportes: el tenis, la equitación, el tiro con arco o el esquí eran deportes de ricos. El deporte, por lo tanto, no sólo establecía diferencias de género, sino también entre clases sociales.

Curiosamente son deportes individuales, dato que resulta muy significativo, si se considera el individualismo imperante entre las clases altas. El Régimen, sin embargo, prefería los deportes colectivos, puesto que se creaban lazos de solidaridad entre las deportistas. Como señalan Viuda-Serrano y González, el fascismo consideraba el deporte como un hecho de masas y no individual ${ }^{47}$. Esto se aprecia desde el punto de vista cuantitativo en los noticiarios analizados. Los deportes colectivos suponen el 65\% del total de las noticias cinematográficas editadas por Luce entre 1928 y $1943^{48}$. Este especial interés del Régimen y del noticiario fascista por los deportes colectivos se demuestra también en el hecho de que hasta los deportes individuales son presentados de forma colectiva, es decir, no hay casi planos de cada una de las deportistas por separado, sino que se presenta a un grupo de mujeres

44. Una Academista de Orvieto recuerda que «las más altas siempre eran colocadas en primera fila, para dar buena impresión. Yo era muy guapa, pero muy pequeñita, y estaba siempre detrás, así que en las fotos no se me veía nunca (...) A veces, a alguna se la eliminaba de la exhibición de gimnasia porque estaba gorda. Esta juventud del Littorio tenía que ser perfecta (MOTTI, Lucia y ROSSI CAPONERI, Marilena. Op. cit., p. 204).

45. En la Academia de Orvieto, por ejemplo, se controlaban las comidas de modo muy riguroso.

46. En Luce se aprecia el tipo de vestimenta que tenían que usar tanto patinadoras como esquiadoras: ropa cara poco accesible para las clases más pobres.

47. Viudd-SERRAnO, Alejandro y GONZÁlEZ AJA, Teresa. Op. cit., p. 49.

48. La mayor parte son pruebas de gimnasia rítmica colectivas: Giornale Luce A0357 (sin día -06-1929) «Ejercicios gimnásticos de la ONB en Perugia»; Giornale Luce B0686 (29-05-1935) «Bolonia. Prueba gimnástica de las Jóvenes Italianas»; Giornale Luce C0147 (27-05-1941) «Actividades de la G.I.L. Florencia. Prueba anual de la G.I.L. Presentes la princesa de Piemonte, la duquesa Ana D’Aosta y los principitos»; etc.

Feminismo/s 21, junio 2013, pp. 183-203 
practicando un determinado deporte: varias jóvenes ejercitándose a la vez en el tiro con arco, o un grupo de patinadoras danzando en una pista, etc ${ }^{49}$.

El anonimato de las deportistas se rompe sólo en alguna ocasión cuando el narrador de Luce nombra a las ganadoras de las pruebas o campeonatos ${ }^{50}$. Les dedica algún plano más corto, pero de breve duración. No se exalta ni se utilizan adjetivos ponderativos para remarcar la hazaña.

\section{Conclusiones: el deporte femenino fuera de las pantallas}

El deporte femenino es percibido por el público de los noticiarios como inferior y menos interesante. Así, en los noticiarios Luce sólo adquiere relevancia como noticia cuando se trata de exaltar al Régimen y a los deportistas italianos. En contradicción con el ambiente y la opinión generalizada, el Régimen impulsó la actividad femenina en todos los sectores que se referían a la educación física: pedagógico, técnico, organizativo. Así, en la segunda mitad de los años treinta, el número de noticias sobre deporte femenino es considerablemente mayor que en la primera mitad. De las noticias analizadas, sólo el 15\% datan de entre 1928 y 1934. El 85\% restante corresponden al período comprendido entre 1934 y 1943.

Estos datos no resultan extraños si se considera que la mayor parte de estos deportes son practicados por las jóvenes pertenecientes a las organizaciones fascistas ${ }^{51}$, lo que representa una ocasión para mostrar en las pantallas de cine los logros de las mismas. En el 70\% de las noticias, las deportistas pertenecen a la GIL o son Piccole o Giovani Italiane ${ }^{52}$.

Además, a partir de 1934 aproximadamente, se produjo un aumento en la práctica del deporte entre las jóvenes, fruto de la política fascista de la mejora de la raza. Se introdujo el deporte en las escuelas para conseguir el objetivo de un cuerpo sano, que en el caso de las mujeres garantizaría una prole sana.

49. Son claros ejemplos, entre otros: Giornale Luce A0713 (sin día -01-1931) «En Roma las Jóvenes Italianas practican el tiro con arco»; Giornale Luce B1514 (17-05-1939) «Merano. Los campeonatos nacionales femeninos de gimnasia»; etc.

50. De las 65 noticias analizadas, sólo en tres ocasiones se menciona el nombre de las deportistas. Este interés por las ganadoras de pruebas deportivas coincide con el cambio en la política deportiva en los años 30 , cuando las victorias en deporte se convierten en un elemento fundamental para la política exterior (VIUDA-SERRANO, Alejandro y GONZÁlEZ AJA, Teresa. Op. cit., p. 49).

51. El 9 de abril de 1928 el gobierno prohibió todos los grupos deportivos no fascistas.

52. Ejemplos son: Giornale Luce A0849 (sin día -09-1931) «Exhibiciones deportivas de las Giovani Italiane»; Giornale Luce B0682 (22-05-1935) «Giovani Italiane en el Foro Mussolini para el Concurso Nacional de Gimnasia Estética»; Giornale Luce B1380 (2809-1938) «Milán. Los campeonatos femeninos de la GIL»; etc. 
Sin embargo, resulta significativo el hecho de que los deportes más practicados por las jóvenes italianas en aquel periodo no sean los más mostrados por las cámaras de Luce. Se trata del baloncesto, natación y atletismo. En el noticiario, no hay ninguna referencia a la natación, y sí a los otros dos deportes. Probablemente la natación era tabú para las cámaras de Luce porque significaba mostrar los cuerpos medio desnudos de las nadadoras, algo que podría resultar escandaloso para los sectores más conservadores de la población. El atletismo, en particular, es uno de los deportes que tienen como contexto el Foro Mussolini, máxima representación de la arquitectura civil fascista. Es uno de los deportes individuales con más presencia en Luce, a pesar de las reticencias de algunos jerarcas del Régimen que consideraban pornográficas algunas pruebas y sobre todo la indumentaria que las deportistas debían llevar.

La retórica oficial consideraba el deporte como el reino de la promiscuidad: las jóvenes tenían la oportunidad de conocer y compartir actividades con grupos de chicos de su misma edad. Esto era visto como un escándalo. De ahí que se prohibieran los deportes mixtos y se organizaran los horarios de deporte de tal manera que se evitara el contacto entre ambos sexos en el campo de deportes. Para evitar la promiscuidad se impusieron una serie de normas:

Las atletas no deberán nunca, bajo ningún concepto, pasar por el recinto deportivo sin endosar los pantalones largos y sólo se los quitarán en el momento de las competiciones. Los pantalones cortos de competición no deberán ser nunca demasiado cortos y las camisetas deberán ser de media manga ${ }^{53}$.

Aunque el número de noticias sobre deporte femenino es mucho menor que el del masculino ${ }^{54}$, no se manifiesta en Luce la intención de evitar el tema, y mucho menos de desvirtuarlo. Bien es cierto que los deportes masculinos son considerados superiores ${ }^{55}$ : en ellos se requiere mayor poder y fuerza física. Pero esto no quiere decir que los femeninos sean infravalorados. Se aceptan y se exaltan manifestaciones deportivas femeninas tales como la gimnasia rítmica o el patinaje artístico ${ }^{56}$. No son deportes de competición, sino más bien

53. Giuntini, Sergio. «La donna e lo sport in Lombardia durante il fascismo», en Congreso Donna Lombarda (1860-1945), Milán, 1989.

54. Sólo de atletismo masculino se han contabilizado 233 noticias cinematográficas entre 1928 y 1943.

55. Este auge del deporte masculino se relaciona con el auge del deporte como espectáculo de masas en el periodo de entreguerras en todos los países europeos.

56. Como ejemplo: Giornale Luce C0109 (13-01-1941) «Patinaje. Génova. Algunos momentos de las competiciones nacionales de patinaje artístico femenino». El narrador se refiere a las patinadoras de la siguiente manera: «virtuosas del arabesco y de la pirueta se suceden delante del público, compitiendo en gracias y habilidades. Vencedora absoluta la campeona Franca Grimaldi di Napoli». 
exhibiciones. Son deportes apropiados para las mujeres, como lo eran todos los deportes que permitieran un mayor desarrollo de la capacidad de procreación femenina.

Gracias a la difusión del deporte femenino en las escuelas y a través de las organizaciones fascistas como la G.I.L., las jóvenes italianas tuvieron la oportunidad de participar en la vida pública del país y de salir del ámbito familiar gracias a las excursiones o a los ensayos extraescolares. De ahí que muchos vieran el deporte femenino como motivo de emancipación y una amenaza para la hegemonía masculina.

En todos los pueblos los deportes femeninos demuestran que son uno de los factores más decisivos del alejamiento de la mujer de la familia, y por lo tanto, de la decadencia demográfica y de la pérdida del pudor (...) El deporte femenino es un factor potente de lo que ahora es llamado ideal de la desnudez, cuyas consecuencias sobre la moral general en la vida familiar y sobre el desarrollo demográfico no dejan ninguna duda ${ }^{57}$.

Así pues, aunque el deporte femenino se puso al servicio de las necesidades propagandísticas del Régimen, fuera de la representación estereotipada de los medios de comunicación oficiales como Luce, existía una realidad muy diferente en la que numerosas mujeres se dedicaban a la práctica de deportes vetados en las pantallas de cine o encontraban en las actividades deportivas una forma de emancipación y autonomía.

\section{Referencias bibliográficas}

BERNAGOZZI, Giampaolo. Il mito dell'immagine. L'immagine del mito. Bolonia, Editrice Clueb, 1983.

Canella, Maria y Giuntini, Sergio (Eds.). Sport e fascismo. Milán, Franco Angeli, 2009.

CAnNistraro, Philip. La fabbrica del consenso. Fascismo e mass media. Roma-Bari, Laterza, 1975.

DE Grazia, Vittoria. Le donne nel regime fascista. Venecia, Marsilio Editori, 1993.

Diel, Louise. La generazione di Mussolini. Milán, Mondadori, 1934.

GonZÁlez AJA, Teresa (Ed.). Sport y autoritarismos. La utilización del deporte por el comunismo y el fascismo, Madrid, Alianza, 2002.

FABBRI, Sileno. L'Opera Nazionale per la Protezione della Maternità e dell'Infanzia. Milán, Mondadori, 1932.

FollaCCHIO, Sara. «Donne e modelli culturali nel ventennio», en «Trimestre», número 1-2, 1985.

57. Loffredo, Ferdinando. Politica della famiglia. Milán, Bompiani, p. 29. 
GEMELli, Agostino. L'educazione fisica della donna. Volumen III. Milán, Soc. Edit. Vita e pensiero, 1926.

GRILLENZONI, Carlarberto. I caratteri del fisico e del vestire considerati come fattori demografici. Roma, Ist. Poligrafico dello Stato, 1931.

GiUnTINI, Sergio. «La donna e lo sport in Lombardia durante il fascismo», en Congreso Donna Lombarda (1860-1945), Milán, 1989.

GORI, Gigliola. Italian fascism and female body. Sport, submissive women and strongs mothers. Nueva York, Routledge, 2004.

ISIDORI FrASCA, Rosella. Il duce le vuole sportive. Bolonia, Patrón Editore, 1988.

Loffredo, Ferdinando. Politica della famiglia. Milán, Bompiani, 1934.

Mangan, J.A. (Ed.). Militarism, Sport, Europe. War without Weapons, London, Frank Cass, 2003.

MONDELlo, Elisabetta. La nuova italiana. La donna nella stampa e nella cultura del Ventennio. Roma, Editori Riuniti, 1987.

Montero, Julio y Paz, María Antonia. Creando la realidad. El cine informativo. 1895-1945. Barcelona, Ariel Comunicación S.A, 2002.

MotTi, Lucia y Rossi CAPOnERI, Marilena. Accademiste a Orvieto. Donne ed educazione física nell'Italia fascista (1932-1943). Perugia, Quattroemme, 1996.

Poggi-Logostrevi. Cultura fascista della donna (de estetica femminile). Milán, Hoepli, 1938.

Rossi, Gaetano. Educazione fascista. Milán, Mondadori, 1942.

VACCARI, Ida. La donna nel ventennio fascista (1919-1943). Milán, Vangelista Editore, 1978.

ViudA-SERRANO, Alejandro y GonZÁlez AJA, Teresa, «Héroes de papel: El deporte y la prensa como herramientas de propaganda política del fascismo», en Historia y Comunicación Social, Volumen 17, 2012, pp. 41-68.

Zagarrio, Vito. Cinema e fascismo: film, modelli, immaginari. Venecia, Marsilio, 2004. 